\title{
MARIA HELENA PATTO, MINHA ORIENTADORA
}

\author{
Silvia Helena Vieira Cruz ${ }^{1}$
}

Resumo: O encontro com a professora Maria Helena Patto na graduação em Psicologia influenciou profundamente as minhas opções teóricas, profissionais e políticas. As suas ideias e posições, que me impressionaram nesse momento, adquiriram mais sentido ao longo da sua orientação da minha dissertação de mestrado e tese de doutorado. Na dissertação, ouvi um grupo de crianças pobres para acompanhar as transformações da representação de escola durante o seu primeiro ano nessa instituição. A tese investigou como a escola se apropriava do projeto Ciclo Básico, buscando compreender o processo de mudança em curso. Nesses trabalhos, ficou clara a necessidade de procurar apreender o ponto de vista dos sujeitos que integram as instituições educativas e situar os fatos historicamente, considerando as suas relações com o contexto socioeconômico, político e cultural.Também a capacidade de me indignar diante de situações que desrespeitam a dignidade humana são parte do meu aprendizado com a Maria Helena.

Palavras-chave: Características do orientador. Orientação educacional. Metodologia. Ambiente escolar.

1 Agradeço aos Professores Doutores Maria Cristina Kupfer e José Leon Crochik o honroso convite para participar deste dossiê em homenagem à Professora Doutora Maria Helena Souza Patto. 
Senti-me muito honrada e mesmo emocionada com a possibilidade de participar deste dossiê, que promove uma reflexão sobre a importância da obra da professora Maria Helena Souza Patto, bem como seu alcance e desdobramentos no cenário da psicologia educacional brasileira. Esses sentimentos me moveram a aceitar a proposta de tratar do seu trabalho como orientadora, sem considerar racionalmente a grande complexidade e dificuldade dessa tarefa, e são eles que marcam esse texto.

Conheci a professora Maria Helena em meados da minha graduação no Instituto de Psicologia da USP, para onde eu havia ido com o objetivo de me formar como psicóloga clínica. No entanto, hoje, trabalhando há muito tempo na área da Educação, o meu maior orgulho profissional é ser chamada de "amada mestra". E sei da influência marcante da Maria Helena no meu percurso, que passou pela experiência como psicóloga escolar e me levou a ser a professora que sou. Assim, me é impossível pensar na sua presença na minha vida profissional trazendo apenas os meus dois trabalhos orientados por ela, a dissertação de mestrado e a tese de doutorado. As suas ideias e posições começaram a ter importância para mim bem antes de, oficialmente, ser sua orientanda.

Acredito que o início da orientação da Maria Helena aconteceu durante a primeira experiência como sua aluna, na disciplina da graduação Psicologia Escolar e problemas de aprendizagem. Nessa ocasião, surpreendi-me por ela indicar um texto (já não lembro o título nem o nome da autora) que trazia críticas à "teoria" da privação cultural e a citava como sendo uma das responsáveis pela introdução acrítica dessa forma de compreender o fracasso escolar das crianças pobres no nosso país. A surpresa pelo inusitado logo se transformou em admiração pela sua coragem de se expor, trazendo à discussão um momento do seu percurso do qual ela certamente não se orgulhava. Fiquei fascinada por essa demonstração de rigor e compromisso com a verdade.

Nunca esqueci esse episódio também porque ele é exemplar acerca de alguns aspectos fundamentais à atividade de pesquisa, os quais foram paulatinamente fazendo cada vez mais sentido para mim. Uma delas é a necessidade de se contextualizar os fatos, situando-os historicamente: naqueles anos em que ela aderiu a essa "teoria",se identificava nas características genéticas (portanto, imutáveis) das próprias crianças as causas do insucesso no seu processo de escolarização; então, parecia um avanço atribuir esse insucesso a supostas carências do seu meio cultural. Afinal, isso era passível de ser "compensado" através de programas específicos, transformando as possibilidades de sucesso dessas crianças, o que passava a ser bastante viável, e trazendo otimismo para as suas vidas.

Por outro lado, a explicação que Maria Helena apontou para a mudança na sua forma de ver esse tema traz outro ponto fundamental:quando ela passou a ter contato direto com as supostas crianças carentes, começou a duvidar dessas carências. Nos seus contextos socioculturais, entre 
os seus pares, elas mostravam-se bastante competentes: comunicavamse, brincavam, aprendiam e ensinavam muitas coisas que tinham sentido para elas. Fiquei impressionada com essa busca da verdade, esse esforço em "ver com os próprios olhos", procurando tirar conclusões a partir do que é percebido, não permitindo que as ideias hegemônicas que circulam se interponham ao que a experiência indica ser a realidade (mesmo considerando que o nosso olhar é sempre marcado por conhecimentos e valores presentes no nosso meio).

Por fim, esse episódio deixou claro que a apropriação de conceitos originados de outras áreas de conhecimento, especialmente das Ciências Sociais, foi importante para a percepção de que a "teoria" da carência cultural é portadora de estereótipos e preconceitos sociais a respeito dos pobres, e do caráter ideológico dessa explicação. Assim, as discussões sobre esse tema explicitaram a necessidade de expandir as possibilidades dadas pela Psicologia para a compreensão dos fenômenos nos quais o homem está implicado. Na verdade, de forma incipiente, começou a ficar patente a necessidade de se pensar o próprio conhecimento produzido pela Psicologia. E, como Maria Helena afirma,

A reflexão sobra a Psicologia só se realiza quando o conhecimento que a constitui é analisado à luz da Sociologia do conhecimento, ou seja, de uma Sociologia voltada para o estudo das interpretações da realidade humano-social, em busca da perspectiva de classe a partir da qual elas foram construídas. (Patto, 1997, p. 54)

Gostaria de registrar também que, ainda durante a graduação, tive a oportunidade de ser monitora da Maria Helena. Nessa condição, pude acompanhar sob outro ângulo o seu trabalho como professora e aprender sobre a importância de levar a sério cada uma das atividades que fazem parte dele: não só preparar as aulas, mas avaliar trabalhos e provas, atribuir notas, registrar as presenças dos alunos... Ainda hoje considero que essas não são tarefas "menores", mas podem ter mais efeito formativo do que os conteúdos trabalhados. Na minha experiência docente, a tentativa de realizar tais tarefas com rigor e responsabilidade tem na Maria Helena uma referência fundamental de respeito aos alunos.

\section{Dissertação: Desejo de escutar as crianças}

A minha dissertação de mestrado, $A$ representação de escola em crianças da classe trabalhadora, foi realizada em meados dos anos 80 (penso que fui das primeiras orientandas da Maria Helena²).Meu objetivo maior

2 Lembro que fiquei muito contente quando vi na lista divulgada pela Pós-Graduação que estava entre as orientandas da Maria Helena; no entanto, por questões burocráticas, de início fiquei sob a orientação do professor Nelson Rosamilha. 
era apreender as expectativas, as ideias, os desejos e receios de crianças pobres sobre a escola e como tudo isso ia se modificando ao longo do seu primeiro ano de frequência a essa instituição e tentar compreender como se davam essas modificações. Já havia um acúmulo de informações acerca do percurso escolar dessas crianças, bastante marcado pela negação do seu direito de aprender. No entanto, me interessava ouvi-las diretamente, tentando saber delas próprias como pensavam e se sentiam a respeito da sua vivência escolar, não através de seus professores e familiares, como era feito.Vale lembrar que naquela altura não se contava com as contribuições da Sociologia da Infância, não se falava em criança como ator social.

Pude contar com todo o apoio da Maria Helena para a realização desse trabalho, que se constituiu numa grande aventura, tanto pelo fato de a Teoria das Representações Sociais ser nova para mim como, e principalmente, pela quase falta de referências para pensar e desenvolver a metodologia necessária ao seu objetivo. Como já estava claro que não seria adequado realizar entrevistas convencionais com as crianças, foi preciso arriscar introduzir adaptações de instrumentos utilizados na clínica psicológica (trabalhei nessa área durante alguns anos). Assim, foram feitas adaptações em dois procedimentos do exame psicológico infantil, as Histórias para Completar, da Dra. Madaleine Backes Thomas, e os Desenhos-Estórias, do Dr. Walter Trinca.

As histórias para completar são cinco inícios de histórias, cada um enfocando um aspecto da vida escolar, o qual era contado à criança, incentivando-a a imaginar como a história continuaria; os Desenhos com histórias consistem em solicitar à criança que desenhe qualquer coisa relacionada à escola e, em seguida, pedir uma história baseada em cada uma dessas produções ${ }^{3}$.

A utilização desses instrumentos permitiu apreender as ideias e sentimentos das crianças sobre a escola e a sua trajetória escolar. Além das histórias que elaboraram, foi importante considerar as atitudes das crianças frente à tarefa, a qualidade das suas produções e os comentários adicionais que elas faziam ${ }^{4}$. E o fato de os encontros com as crianças acontecerem nas suas residências (localizadas numa favela e num cortiço próximos à escola) possibilitou o contato direto com as suas condições materiais de vida e com as suas relações familiares.

3 Segundo Trinca (1997), foi a primeira vez que o desenho-história foi utilizado para investigar um tema específico. Em vários trabalhos posteriores tenho usado adaptações semelhantes, que sempre se mostraram muito valiosas.

4 Além dos referidos instrumentos, foram feitas observações na escola que as crianças frequentavam e entrevistas com a professora delas e seus familiares. 
Os encontros iniciais com as crianças aconteceram antes de começarem o primeiro ano do ensino fundamental. Mas, como a representação é um sistema essencialmente dinâmico, "uma atividade de construção e reconstrução do real pelo sujeito" (Mollo, 1979, p. 31), para acompanhar as transformações na representação de escola que aconteciam ao longo e após esse ano, foram realizados vários encontros durante esse período.

O grupo de crianças que acompanhei diminuiu, por motivos alheios à pesquisa, durante o seu percurso e se concentrou em duas meninas, Andrea e Daniele, e três meninos, Fábio, Jânio e Reginaldo. Eles tinham entre seis e sete anos, eram saudáveis, muito curiosos, alegres, gostavam de conversar. Moravam com seus familiares (com quem mantinham ótimo relacionamento) e tinham muitos amigos, especialmente Fábio e Reginaldo. Todos frequentavam a mesma classe de uma escola estadual que não se diferenciava significativamente das demais dessa rede.

O acompanhamento das transformações que sofreram as ideias e sentimentos das crianças acerca da escola ao longo desse primeiro contato com ela trouxe muitas preocupações.

Antes do início do ano letivo, as crianças expressavam principalmente o desejo de aprender muitas coisas importantes, em especial esperavam dominar a leitura e a escrita. A escola parecia uma possibilidade de se transformarem em pessoas mais sabidas, de num sê burro, como dizia o Flávio. Como pesquisas posteriores também indicaram ${ }^{5}$, outra expectativa das crianças era de na escola haver oportunidade de encontrar amigos e brincar com eles. Elas mostram vivamente a grande importância da presença de brinquedos no espaço escolar, associando-os a outros elementos que o compõem:

Vai ser bom. Vai ser bom porque lá tem um corredor pra mim brincar e eu tenho uma amiga lá, eu já conheço ela.... Os alunos são alegres, eles gostam de mim, brincam comigo. (Daniele)

Lá tem brinquedo, tem boneca, tem carro, tem bola, na classe tem mesa, cadeira, aqueles armarinhos de botar livro. (Andrea)

Às vezes tem ... na escola, assim de criança, tem brinquedo pra gente brincar.... Na classe tem as cadeiras, né? Tem a lousa pra gente desenhar, tem as mesas pra gente botar os cadernos, né? (Jânio)

As crianças também expressaram o temor de serem repreendidas por não saberem fazer tarefas ou não se comportarem como deveriam, como expressa o Reginaldo ao completar uma história: [a professora] dis-

5 Por exemplo, Cruz (2002), Campos e Cruz (2006), Andrade (2007), Martins (2009) e Schramm (2009). 
se:"Vá fazer o dever, então vá pro banheiro"[Pra que?] Pra trancar, trancar ele. [Por quê?] Porque não tava fazendo o dever.

De qualquer forma, prevaleciam expectativas e desejos positivos e as crianças mostravam-se ansiosas para que o ano letivo começasse. Inclusive, no início do semestre elas não queriam perder nenhuma aula.

No entanto, no cotidiano da sua experiência escolar, cada vez mais foram se concretizando os seus temores: a escola não se mostrava como um espaço de prazer e aprendizagem; na realidade parecia ser um local em que tinham que mostrar que sabiam. Se não sabiam, não tinham o apoio da professora, mas sim a sua reprovação. Andrea, por exemplo, disse, referindo-se à professora:

É muito boa ela, tia. Mas quando às vezes ela... ela briga... [Às vezes ela briga?] Ô se não briga, briga é muito! A pior coisa é quando ela briga. [Por que ela briga?] Porque... porque eu nunca sei.

As crianças sofriam e se ressentiam muito dessas situações que os envergonhavam perante todos e a eles próprios. $E$ às penalidades que sofriam na escola, somavam-se as domésticas, pois suas famílias percebiam a sua escolarização como forma de elas conseguirem se livrar da condição de pobreza em que viviam e, não vislumbrando nenhuma possibilidade de mudar a escola, tentavam amoldar as crianças às exigências dessa instituição.

Em meados do primeiro semestre a professora já anunciava quem provavelmente iria ser promovido ao final do ano. $E$ as crianças, com exceção de Jânio, começaram a ter sérias dúvidas se estariam entre esses poucos "que já sabem fazer dever mais direito" (Daniela). Nesse contexto, assumia papel fundamental a ajuda de familiares e vizinhos. Jânio ${ }^{6}$ mostrou a consciência disso, ao completar, em meados do ano letivo, a história de um menino que não estava aprendendo o que a professora explicava:

a professora dele disse, no dia que tem a reunião das mães: "O seu filho não sabe nada. Você tem que deixar mais ele em casa pra poder ele vim pra aula." [E o que aconteceu?] Aí ele não foi mais pra aula não. Passou um horror de dia [muitos dias]... Quando ele já tava sabendo mais do que todo mundo, aí ele foi pra aula.[Como ele aprendeu?] Ele... a mãe dele todo dia botava ele pra ler, pra ler... Mas fica até de noite! Aí ele aprendeu. Aprendeu mais do que os outros.

Além de passarem más situações por não aprenderem, as crianças também eram repreendidas por comportamentos considerados inadequados pela professora: a concentração, a postura, os gestos, as comuni-

6 Vale registrar que esse menino, que contava com a ajuda de vários irmãos mais velhos, foi o único do grupo que obteve aprovação para cursar o segundo ano. 
cações entre elas eram alvo de toda a sua atenção. Mesmo Jânio, o que conseguiu amoldar-se melhor às exigências da escola, referia-se com frequência ao ambiente opressivo em que a professora convertia a sala de aula:

A professora briga, que a minha é ruim! Ela só vive brigando.... A minha professora, ela é bruta porque ela chega na classe e vai logo brigando com a gente. "Pessoal, quero que vocês fiquem bem quietos, não falando nunca". Fala assim!

Como estar na escola não trazia prazer para as crianças e a maioria delas não conseguia ver um sentido para lá permanecer, o desejo que predominava era o de fugir, escapar das experiências que lá aconteciam. No entanto, suas famílias não podiam abrir mão da esperança de um futuro melhor ${ }^{7}$. Então, obrigavam as crianças a irem à escola, como disse Andrea, numa de suas histórias:

a mãe dela queria que ela fosse pra escola! Senão, levava uma pisa na bunda ... A menina não quis: "Mamãe, por que a senhora quer que eu vá?"“Minha filha, pra você ... é pra você aprender. Se você não for, eu dou uma pisa [surra] de corda." Aí a menina: "Tá certo, mamãe, eu vou. Eu não quero apanhar."

Algumas crianças não se submeteram, transgrediram as normas e procuraram formas de burlar a escola e a família. Andrea, por exemplo, afirmou gostar muito de "ir buscar qualquer coisa pra tia, fora da classe"e assim conseguir escapar momentaneamente. Mas mesmo tais estratégias podiam ser malsucedidas, como relatou Flávio: "Nós não podia sair nem pra fazer a ponta! Ela:'Ei, ei! Volte pra dentro!'... Quando nós estava assim na porta, ela pegava, puxava nossa orelha". Após algumas fugas da escola, durante o recreio, esse menino deixou definitivamente aquela escola, mesmo enfrentando todas as punições decorrentes dessa decisão: sua mãe narrou que ela "dava tapa nele aqui mode [para] ele ir, o pai dele também deu foi muito nele também, mode ele ir.... Aí ele dizia:'Pode me matar, mas eu não vou!".

A obstinação dessa criança mostra o quanto a frequência à escola era daninha para ele. Para as demais, representava um sacrifício ao qual se submetiam. Para entender esses sentimentos, é preciso considerar que essa experiência escolar significou não só a frustração da possibilidade de aprendizado de quase todas, mas também a perda da própria confiança na capacidade de aprender: Daniele, o caso mais contundente, antes do início das aulas gabava-se de ter "muita facilação [facilidade] pra

7 D.Conceição, avó do Reginaldo, resumiu de maneira dramática:"Se eu tirar meus neto do colégio, pronto! Perdeu todas as esperança da minha vida!'. 
fazer dever difícil', mas apenas alguns meses depois já tinha certeza de que não passaria de ano... Além disso, também cotidianamente foram frustradas as suas expectativas de brincarem e se divertirem, mesmo no recreio. Como resumiu Daniele," a escola é muito ruim, a gente não faz nada lá, sem brincar e sem nada". . Na classe, a professora centrava-se mais no disciplinamento dos alunos que na promoção das suas aprendizagens. Parecia que a maior lição que as crianças deveriam aprender era a submissão às normas da escola. Isso era captado com bastante clareza pelas crianças, como expressou Andrea, ao afirmar que a personagem de uma história" obedecia todo mundo, só obedecia, só obedecia. A mãe dela quer que ela obedece bem muitão".

Vale destacar que as falas das crianças traduzem o que pode ser observado na escola:às diversas situações em que as crianças eram levadas a se sentir praticamente incapazes de assimilar o que a professora deveria lhes ensinar, somavam-se momentos em que eram publicamente declaradas sujas, desleixadas ou mal-comportadas, enquanto suas famílias eram consideradas displicentes e desorganizadas, enfim, inadequadas. Tais ataques à autoestima das crianças chamavam mais a atenção que a falta de competência da professora para trabalhar os conteúdos propostos, pois não derivavam apenas da precariedade de formação ou carência de supervisão adequada, mas da falta de respeito com essas crianças. Em suma, na relação estabelecida entre a professora e seus alunos predominava a hostilidade e o desrespeito; o consequente medo que isso provocava nas crianças esteve bastante presente na representação que elas construíram de escola.

É preciso registrar também que o que uma instituição provoca nas pessoas nos diz muito sobre ela. Manonni (1977) chama a atenção para isso quando afirma que "os desajustados, que são cada vez mais numerosos, devem ser considerados um sintoma da doença das instituições" (p. 49). Portanto, o fato de apenas uma criança entre cinco ter conseguido ser aprovada ao final do ano letivo revela a inadequação da escola para realizar a sua tarefa. Ao final do ano, D. Conceição disse que achava que" $o$ Reginaldo não aprendeu mesmo nada não" por causa de algumas atitudes dele, mas "também pelo problema dela [professora], porque ela fracassou". Ampliando a sua afirmação,é possível pensar que o fracasso das crianças espelha o fracasso da escola. Ela parece ser eficiente apenas para quem menos precisa dela.

8 Infelizmente, outras pesquisas também apontaram essa percepção das atividades escolares que realizam como nada, isto é, algo que não tem sentido, nem prazer (além dos longos momentos de ociosidade real). Patto (1990), por exemplo, constatou que"o que se ensina e a forma como se ensina tornam a tarefa de ensinar e de aprender uma sucessão de atividades sem sentido que todos, professora e alunos, executam visivelmente contrafeitos e desinteressados" (p. 233). 
Realmente, o acompanhamento das modificações sofridas pela representação de escola dessas crianças foi uma oportunidade para compreender melhor o quanto o desempenho escolar delas é resultado de múltiplos e complexos fatores, boa parte dos quais relacionados à escola. E logo ficou evidente que o desempenho escolar das crianças se refletia não só no modo como elas pensam e sentem a escola, mas também a si mesmas. Assim, a diminuição da autoestima de quase todas elas foi o grande saldo negativo dessa experiência.

Certamente há muitas escolas e professoras mais competentes e, portanto, mais sensíveis aos desejos e necessidades das crianças pobres que constituem a clientela compulsória da escola pública. No entanto, os baixos índices de aprendizagem dos estudantes brasileiros (atualmente aferidos em várias avaliações nacionais e internacionais) indicam que as histórias dessas crianças não são fundamentalmente diferentes das que se desenrolam na maioria de outras escolas do país.

Importa não colocar nos ombros dessas crianças a responsabilidade das dificuldades que enfrentam. Como afirma Patto (1997), em artigo posterior a esse trabalho,

Pesquisas recentes da escola pública de $1^{\circ}$. grau, realizadas a partir de um lugar teórico que a toma como instituição social que só pode ser entendida no interior das relações sociais de produção em vigor na sociedade que a inclui, têm mostrado reiteradamente que essas dificuldades não podem ser entendidas sem que se levem em conta práticas e processos escolares que dificultam a aprendizagem. (p. 48)

Tese: a escuta de outros segmentos da comunidade escolar

Entre os anos de 1984 e 1985 integrei o então recém-inaugurado Serviço de Psicologia Escolar do IPUSP, na ótima companhia de Marilene Proença Rebello de Souza e Cintia Copit Freller. Nas intervenções realizadas em escolas da rede pública da cidade de São Paulo que buscavam esse Serviço, um tema que me instigava era como os integrantes da escola estavam traduzindo, na sua prática cotidiana, o Ciclo Básico, projeto que estava sendo implantado pela Secretaria de Educação do Estado e levantava muitas dúvidas entre professores, crianças e suas famílias. Ao definir, com a ajuda da Maria Helena, o tema da minha tese de doutorado, esse projeto já tinha oito anos de implantação; no entanto, havia diferenças importantes entre a sua proposição original e a forma como as escolas a traduziam na sua prática e muitas questões permaneciam pouco esclarecidas entre os integrantes da comunidade escolar. Assim, optei por investigar A construção do Ciclo Básico pela escola, acreditando que a 
compreensão das peculiaridades da apropriação ${ }^{9}$ desse projeto específico poderia oferecer elementos úteis à implantação de propostas de transformação que concorressem para adequar a escola aos reais interesses da classe dominada.

Para entender essa iniciativa do governo do estado de São Paulo, foi importante retomar o problema da seletividade da escola no nosso país, pois o Ciclo Básico surgiu como mais uma forma de "contornar o problema da seletividade que ocorre em todo o sistema de ensino no Brasil e de forma mais acentuada nas séries iniciais" (Duran, 1989, p. 3, itálico nosso). Também foi necessário ter notícias acerca de outras reformas ou mudanças ocorridas nas últimas décadas na escola pública paulista, uma vez que essas experiências marcavam a forma como o Ciclo Básico era percebido tanto pelos professores como pelas famílias. $O$ estudo das iniciativas que pretenderam algum tipo de inovação educacional evidenciou que o papel do professor como efetivo agente de mudança não foi suficientemente considerado pelos seus idealizadores, pois pareciam não levar em consideração (ou dar a devida importância) uma série de aspectos que compõem a sua identidade profissional e são determinantes para a sua aceitação e engajamento.

Em relação ao Ciclo Básico parece que não foi muito diferente. Esse projeto envolveu, em seu primeiro ano de implantação, 1984, cerca de 30.000 professores e no seu segundo ano estendeu-se a 50.000 professores. A decisão de implantar num curto espaço de tempo, numa rede de ensino tão extensa, um projeto que implicava em várias mudanças no funcionamento da escola (como a ampliação da jornada escolar) e na prática pedagógica (especialmente a não reprovação do aluno ao final do Ciclo Básico Inicial - antigo primeiro ano) era, no mínimo, ousada. O gigantismo da rede e a sua organização impuseram a mediação de várias instâncias para a transmissão das informações e ideias que compunham esse projeto, o que dificultou a sua compreensão pela escola. Nesse sentido, vale destacar que a nova proposta de alfabetização, baseada nas contribuições da psicogênese da língua escrita, de Emília Ferrero e Ana Teberosky, foi introduzida através de encontros, conferências e cursos que pretendiam propor uma reflexão epistemológica sobre esse processo, mas chegou de forma precária aos professores e provocou resistência.

90 conceito de apropriação é utilizado por Justa Ezpeleta e Elsie Rockwell para entender a escola. A partir das ideias de Antonio Gramsci sobre as relações entre sociedade política e sociedade civil, entre a estrutura econômica e a superestrutura cultural, e entre ideologia e contraideologia, essas autoras acreditam que a construção social de cada escola é sempre uma versão local e particular do movimento histórico de amplo alcance no qual está inserida. Nela se concretizam e se atualizam a cada instante as correlações de força e demais aspectos que compõem a trama real em que se realiza a educação. E essa trama precisa ser conhecida, pois ela é, ao mesmo tempo, o ponto de partida e o conteúdo real de novas alternativas pedagógicas e políticas. 
A escola escolhida para a realização desse trabalho era de porte médio, tinha doze salas de Ciclo Básico (conhecido como CB) e nela a jornada única foi introduzida desde o primeiro ano de sua instituição, 1988. Era localizada num bairro com muitos contrastes, onde coexistiam antigas habitações que expunham o baixo padrão de vida de seus moradores, novas residências típicas de classe média que começavam a se instalar e uma grande favela. Era das casas mais modestas e da favela que procediam as crianças e jovens que frequentavam essa escola.

Para acompanhar o processo de apropriação do projeto Ciclo Básico, tornou-se imprescindível conhecer de perto a escola, tentando apreender o seu cotidiano. Nesse processo, as dificuldades enfrentadas foram imensas e entre elas destaco o risco de tomar como verdades inquestionáveis informações recolhidas por outros, se deixar guiar pelo senso comum, vendo através de lentes que facilmente tornam homogênea essa realidade, acomodando-a a certas categorias ou preconceitos que a simplificam. Não tive a pretensão de superar essas dificuldades, mas de que a compreensão delas ajudasse a orientar melhor a busca empreendida.

Considerei que a abordagem etnográfica seria a melhor opção para atingir os objetivos desse trabalho, que supunha a microanálise da vida escolar. Assim, realizei observações frequentes e prolongadas que incluíram todos os tipos de atividades realizadas na escola, assim como as que aconteceram fora dela e envolviam as professoras de CB: aulas, reuniões (com professores, pais, coordenadoras de $\mathrm{CB}$ da região administrativa a qual a escola pertencia etc.), discussões ocorridas na hora de trabalho pedagógico - HTP ${ }^{10}$, festas, encontros pedagógicos e cursos destinados aos professores de CB promovidos pela Secretaria de Educação do estado de São Paulo. Os almoços com as professoras nos dias da HTP e as conversas da sala dos professores mostraram-se também preciosos para apreender as ideias que circulavam sobre esse projeto. As observações das salas aconteceram semanalmente e focaram quatro turmas que identifiquei como representativas de "tipos" que a prática havia consagrado (e já expressavam uma face da apropriação desse projeto): uma de alunos novos no CB Inicial, uma de "alunos repetentes do CB Inicial",outra de "CB Intermediário" (não mencionada em nenhum documento oficial sobre o CB) e ainda outra de "CB Final" (correspondente ao $2^{\circ}$ ano do Ensino Fundamental). Todos os indivíduos que na escola se apropriavam desse projeto produzindo "a diversificação, a alteração, a historização da realidade escolar" (Ezpeleta \& Rockwell, 1989, p. 72) foram entrevistados: o diretor, a coordenadora de CB, as professoras das turmas observadas, um

10 Trata-se da utilização das seis horas de trabalho pedagógico, previstas na implantação da Jornada Única no Ciclo Básico; aconteciam semanalmente. 
grupo de crianças e seus familiares de cada uma dessas turmas. Também foram entrevistados vários diretores, coordenadores e professores de $C B$ de escolas da mesma Delegacia de Ensino da escola pesquisada, assim como a monitora de Ciclo Básico dessa Delegacia e alguns integrantes de órgãos centrais da Secretaria de Educação. Complementando essas duas formas básicas de aproximação do objeto de pesquisa (observações e entrevistas), considerei importante um olhar atento aos documentos relativos à criação e implantação do Ciclo Básico e a alterações que foram sendo introduzidas ao longo do tempo; paralelamente, na escola em foco, realizei o exame das listas de alunos de todas as turmas de $C B$, desde a implantação do projeto até 1991 , como forma de conhecer as trajetórias escolares desses meninos, meninas e adolescentes.

Ao longo de todo esse trabalho, foi possível perceber, como afirmam Ezpeleta e Rockwell (1989), a "história e existência não documenta$\mathrm{da}$, através da qual a escola toma forma material e ganha vida"(p.13),que reflete o encontro da vontade estatal com tudo o que é constitutivo da escola. Como essas autoras, considerei ser possível reconstruir a história não documentada analisando a existência cotidiana atual da escola como história acumulada e buscar, naquele momento presente, os elementos estatais e civis que constroem a escola. Nesse sentido, foi importante conhecer, a partir de indicações da Maria Helena, a noção de vida cotidiana segundo a perspectiva da pensadora marxista Agnes Heller ${ }^{11}$, que se constituiu em ferramenta conceitual básica para a tarefa de

abordar todo o "outro" que também é constitutivo da escola, ou seja, tudo aquilo que o Estado, a partir da sua visão normativa ou categórica, costuma qualificar de 'desvio' das normas. (Ezpeleta \& Rockwell, 1989, p. 21)

A reprovação no Ciclo Básico Inicial, os chamados "remanejamentos de boca"12 e outras estratégias utilizadas pelas professoras para amoldar as determinações contidas nesse projeto às suas próprias crenças e interesses indicam, como afirma Rockwell (1982), o quanto "a norma oficial não se incorpora à escola de acordo com a sua formulação explícita original", mas "é recebida e reinterpretada por uma ordem institucional existente e por diversas tradições pedagógicas em jogo dentro da escola" (p. 10). Vale destacar que a reprovação no Ciclo Básico, que originou a criação de turmas formadas apenas por estudantes reprovados, deu con-

11 A sociologia da vida cotidiana de Agnes Heller permite estabelecer relações entre a vida comum do homem comum e os movimentos da história. Como destaca Patto (1990), na teoria que ela elabora há uma redefinição do sujeito, do lugar e das estratégias de transformação social que ela julga necessária.

12 Prática comum de remanejar alunos para outras salas, após o período em que, oficialmente, isso era permitido; portanto, sem o devido registro. 
tinuidade à reprovação antes existente na $1^{\text {a }}$ série do então chamado $1^{\circ}$ Grau. Assim, a seletividade continuou sendo uma das marcas do nosso sistema educacional, tanto porque ele é sujeito aos interesses dos grupos dominantes, mediados pelo Estado (e a educação de boa qualidade para todos não corresponde a esses interesses), como porque as professoras veem a reprovação como mecanismo importante, inclusive para a ratificação da sua autoridade.

A trama de relações no interior da escola mostrou-se bastante complexa. Era permeada tanto pela solidariedade (que se manifestava nas trocas de informações relativas a outros papéis das professoras, orientações sobre como ensinar determinado assunto, como lidar com os "problemas de indisciplina" dos alunos etc.) como pela egoísta manutenção de privilégios (por exemplo, a "escala" de professores que determina a escolha das turmas), pelas disputas de prestígio (constatadas até na eleição da "Miss Caipirinha"), pela admiração e pelo respeito, pela inveja e rivalidade que promoviam alianças e agregavam grupos contra outros. $E$ essa trama reflete, inclusive, o que acontecia fora dos muros da escola. Assim, por exemplo, a valorização das orientações dadas pela colega mais experiente estava ligada à precária formação inicial das professoras e aos ineficientes processos de "reciclagem" oferecidos; o desprestígio social aumentava a necessidade das professoras buscarem, internamente, fontes de reasseguramento do seu valor.

Outro aspecto que chamou muito a atenção no trabalho de campo foi a predominância da mentalidade burocrática, que anulava a reflexão, a criação, a aprendizagem, a mudança; provocava sérias inversões. São exemplos dessas inversões: a pouca importância dada ao que as professoras discutiam na "reunião de HTP" contrastando com o valor dado à existência dessa reunião e ao registro da presença das participantes; a norma do aluno ser impedido de participar das aulas se estivesse sem o uniforme da escola, não se considerando sua real possibilidade de adquiri-lo, nem o seu desejo (e muitas vezes o da sua professora) de participação nas atividades; o fato de se dispensar os alunos para que os professores pudessem "por em dia toda a papelada" exigida pela Delegacia de Ensino ${ }^{13}$. E tudo parecia muito normal, de acordo com o modo burocrático de pensar e gerir, no qual predomina o formalismo e a ação administrativa se desumaniza.

Na relação entre as professoras e os alunos e suas famílias, apesar de dominada por preconceitos e estereótipos, também tinha lugar a consideração e mesmo o carinho. A máscara autoritária podia desmancharse num sorriso diante de um comentário sapeca; algumas situações leva-

13 Vale registrar que um dos documentos, preenchido no segundo semestre letivo, teria a função de apresentar os alunos para a professora do ano em curso. 
vam a professora a confessar:"Precisava ver que bonitinho, nunca pensei que ela [uma criança] pudesse fazer isso!!!!". Também aqui é preciso considerar que o padrão geral, as contradições e ambiguidades do comportamento das professoras frente à clientela da escola eram marcadas pela ideologia dominante na nossa sociedade. Assim, elas incorporavam no seu pensamento e no seu discurso os preconceitos a respeito dos pobres, presentes tanto no senso comum como no discurso aparentemente científico que os legitimava, ao qual tinham acesso nos cursos de formação ou "reciclagem", através da mídia etc.

É preciso lembrar também que as mudanças concretizadas no interior das escolas são realizadas por pessoas movidas por seus interesses, desejos e crenças. E entre os interesses dessas professoras estava sobreviver da maneira menos doída e trabalhosa possível nas condições de trabalho que lhes eram oferecidas; entre os seus desejos geralmente não se encontrava empenhar-se na busca de formas alternativas para estimular o aprendizado dos seus alunos, pois em meio às mentiras a que a ideologia dominante as levou a acreditar estava a incapacidade intelectual, afetiva e moral das pessoas pobres, usuárias da escola pública. Como esperar que essas profissionais se entusiasmassem, de fato, com esse tipo de projeto, empunhassem de uma hora para outra a bandeira da igualdade de oportunidades e, inclusive, se tornassem construtivistas?

A opção pelo construtivismo foi um dos aspectos mais divulgados da proposta pedagógica do Ciclo Básico e a que implicaria em maiores mudanças na prática docente das professoras. No entanto, o discurso e as ações dos órgãos centrais da Secretaria de Educação acerca da adoção dessa teoria por toda a rede pública estadual parecia corresponder a uma compreensão simplista da mesma, além de desconsiderar algumas de suas ideias básicas. Seria fundamental partir da reflexão sobre a prática profissional das professoras, uma preocupação quase ausente nos encontros de divulgação do construtivismo, onde as professoras permaneciam passivas diante do que era "passado", não encontrando espaço para pensar sobre os saberes que vinham construindo na sua experiência, nem para expressar suas percepções, dúvidas e críticas em relação ao que lhes era apresentado. Por outro lado, seria de fundamental importância promover o estudo aprofundado das ideias básicas dessa teoria, além de providenciar o acompanhamento sistemático das tentativas que as professoras viessem a empreender no sentido de incorporar a perspectiva construtivista na sua prática diária, o que levaria à busca de aprofundamento teórico. A professora, nesse movimento dialético entre a ação e a reflexão, poderia ir construindo a sua prática pedagógica construtivista. Isso não aconteceu e as professoras não conseguiam entender nem a teoria nem a sua contribuição para a consecução de seus objetivos eminentemente práticos. 
Outro ponto também parecia dificultar a adoção do construtivismo por essas professoras: para perceber o aluno como sujeito do seu desenvolvimento, agente ativo do seu processo de aprendizagem, construtor de conhecimentos, seria preciso, de fato, acreditar na capacidade desse aluno refletir, estabelecer relações, julgar, articular ideias, tirar conclusões, raciocinar. Isso exigiria uma mudança de postura radical em relação ao usuário da escola. E essa revolução interna implicaria outra, uma revolução copernicana no interior da sala de aula: a fonte do saber não poderia continuar sendo exclusivamente a professora, ela precisaria tomar os alunos, no mínimo, como coautores do processo de aprendizagem deles, deixar de ser o centro e coordenar esse processo. No entanto, é necessário ter claro quão difícil seria essa mudança, quantos estereótipos e opiniões seria preciso abandonar, o grau de ansiedade que isso provavelmente levantaria, a intensidade das resistências que seria necessário superar. Trata-se, nas palavras de Bosi (1992), de uma verdadeira conversão.

De acordo com Agnes Heller $(1987,1992)$, a apropriação do mundo é duplamente transformadora: ao mesmo tempo em que o indivíduo é modificado pela apropriação das coisas, dos costumes etc., esse processo nunca se dá de forma pura, pois ele imprime nessa apropriação suas características pessoais. No caso da apropriação do Ciclo Básico pela escola, no entanto, pode ser constatado que houve grandes deformações. $\mathrm{Na}$ busca de compreensão desse fato foi muito útil o conceito de ultrageneralização, uma das características do pensamento cotidiano, segundo Agnes Heller: são ultrageneralizações os juízos provisórios necessários para que possamos viver em comunidade, mas os juízos provisórios que se enraízam na particularidade e são fundados na fé são pré-juízos e préconceitos, passando a ser imunes à experiência que deveria confirmá-los ou não. Foi levantada a hipótese de que a percepção das professoras sobre o Ciclo Básico tenha sido marcada por experiências anteriores de inovação educacional que elas consideraram negativas, cristalizaram-se em preconceitos e dificultaram essa percepção. Mas foi preciso considerar também que no próprio projeto encontra-se o germe das deformações que ele sofreu, tendo em vista a visão depreciativa das crianças que sutilmente nele transparece, algumas estratégias que ele prevê para"contornar" os problemas de aprendizagem, a forma como ele foi imposto e a maneira como se deu o seu acompanhamento.

A consequência mais notável de tudo isso foi a resistência à mudança. Na tentativa de entender essa resistência, também foram importantes algumas ideias de Pichon-Rivière (1982) sobre esse processo. Ele considera que são as técnicas defensivas que estruturam a resistência à mudança e estas são mobilizadas pelo aumento das ansiedades de perda e ataque. É possível identificar na exacerbação do valor de uma teoria que as professoras não conheciam e a consequente depreciação dos sabe- 
res que elas construíram ao longo da sua experiência ${ }^{14}$ (à qual se soma a desvalorização que percebiam do seu trabalho), a origem do sentimento de perda, especialmente a perda da autoimagem de competência. Parece razoável supor que a ansiedade de ataque seja mobilizada pela ameaça que o novo representava para as professoras, pois elas se viam destituídas das armas que pensavam possuir e ainda não tinham nas mãos nada que as substituíssem (o construtivismo, tão valorizado pelos técnicos e tão desconhecido para elas); em outras palavras, nesse momento, essa novidade serviu apenas para roubar a razoável segurança que elas possuíam.

Embora toda mudança seja fonte de ansiedade, pois implica perdas e gera insegurança, esse momento precisa ser elaborado e superado, uma vez que os mecanismos defensivos, mobilizados pela intensificação de medos básicos, cristalizam estereótipos, provocam dissociações (principalmente entre o pensar, o atuar e o sentir) e levam ao estancamento da possibilidade de aprender com as experiências proporcionadas pela vida; nas palavras de Pichon-Rivière (1982),"operam como obstáculo epistemológico na leitura da realidade" (p. 19). Assim como Agnes Heller, ele também destaca o interjogo dialético entre as transformações que o sujeito opera no objeto que apreende e as modificações que essa apreensão provoca nele próprio; no indivíduo sadio,"a síntese que resolve uma situação dilemática transforma-se no ponto inicial ou tese de outra antinomia, que deverá ser resolvida nesse contínuo processo em espiral" (p. 3). Conclui que "a saúde mental consiste nesse processo, em que se realiza uma aprendizagem da realidade através do confronto, manejo e solução integradora dos conflitos" (p. 3).

Considerando as dificuldades inerentes aos processos de mudança e, ao mesmo tempo, as possibilidades de ganhos que ele representa, o presente trabalho empreendeu uma tentativa de situar uma contribuição plausível do psicólogo nesse contexto. Considerou que esse profissional, tendo conhecimentos psicológicos necessários ao trabalho eficiente com grupos em processo de reflexão e mudança, poderia ser capaz de atuar como facilitador no longo e árduo processo de ruptura da pauta dissociativa e estereotipada que obstaculariza a aprendizagem. Sua ação poderia, ainda, contribuir para uma maior compreensão e melhor administração dos fatores presentes no processo de mudança, de tal forma que ele não fosse um instrumento de alienação das pessoas nele envolvidas, mas, ao contrário, que essas pessoas (no caso, as professoras) pudessem nele se enriquecer. aposentar. 
O trabalho conclui que, embora não haja lugar para pretensões onipotentes, é certo que há algo a fazer junto a professoras para contribuir na ampliação da sua percepção acerca de seus alunos e das famílias deles, do seu trabalho e da educação na nossa sociedade. Não menosprezando as limitações impostas pelas forças que engendram a estrutura e o funcionamento da escola e, ao mesmo tempo, atento à complexidade do ser humano, o psicólogo poderia auxiliá-las na conquista de uma apropriação da realidade na qual pudessem impor a marca de si mesmas. Como afirma Agnes Heller (1992),

A condução da vida não pode se converter em possibilidade social universal a não ser quando for abolida e superada a alienação. Mas não é impossível empenhar-se na condução da vida ${ }^{15}$ mesmo enquanto as condições gerais econômico-sociais ainda favorecem a alienação. Nesse caso, a condução da vida torna-se representativa, significa um desafio à desumanização. (pp. 40-41, itálicos do autor)

Se, na nossa sociedade alienada, não podemos fugir à alienação, temos de provocar a consciência dessa alienação. Diante da desumanização, valorizar o humano. Onde prevalecem preconceitos e estereótipos, questioná-los. Ao desejo de cega submissão, contrapor o incentivo ao espírito crítico. Negar o primado da heteronomia na busca da autonomia.

\section{Últimas palavras}

Gostaria de concluir esse texto sublinhando, de maneira muito sintética, algumas das grandes aprendizagens que a Maria Helena me proporcionou.

Em primeiro lugar, é preciso destacar a necessidade de não se ater às análises das informações possibilitadas ao nível individual ou micro e ao presente, mas procurar situar os fatos historicamente e buscar entender as suas relações com o contexto socioeconômico e cultural. Essa postura tem ajudado, por exemplo, a não perceber as professoras ou outros profissionais da educação como únicos responsáveis pela prática pedagógica que acontece no interior das instituições de educação infantil (onde tenho centrado o meu trabalho nos últimos anos) ou das escolas; ou a buscar conhecer o processo de expansão das creches e pré-escolas no nosso país, marcado por uma visão preconceituosa em relação aos

A autora toma o termo "condução da vida" de Goethe, referindo-se à possibilidade do homem "construir para si uma hierarquia consciente, ditada por sua própria personalidade, no interior da hierarquia espontânea", comum a toda vida cotidiana. 
pobres e descomprometida com a qualidade, para tentar compreender a precariedade e os equívocos presentes nesses equipamentos.

Nesse sentido, tem se mostrado muito importante procurar entender o papel da educação e da escola na nossa sociedade, considerar os fatores econômicos, políticos e sociais que a influenciam; buscar os nexos entre a ineficiência da nossa escola pública e os interesses da classe hegemônica; lembrar que a instituição educativa é também espaço de contradições, de conflito e de luta e que a própria história da nossa legislação educacional mostra o poder da luta coletiva organizada.

Nessa caminhada, cada vez mais compreendo que é preciso procurar apreender o ponto de vista dos vários sujeitos que fazem parte das instituições educativas. Por exemplo, procurar saber o que pensam, em que acreditam, o que almejam professores, coordenadores, diretores. $\mathrm{E} o$ que significa a experiência educativa para as crianças e jovens que, cotidianamente, frequentam as creches, pré-escolas ou escolas que lhes são impostas? E para suas famílias? Parece que esses sujeitos, especialmente as crianças, ainda são pouco ouvidos, não têm tido reais oportunidades de se expressar. Por isso, as pesquisas que lhes oferecem essa chance têm contribuído para alargar os conhecimentos do que aí acontece e trazido elementos preciosos para se analisar os processos constitutivos da realidade escolar.

A partir da interlocução com a Maria Helena, aprendi também a manter a capacidade de me indignar diante de situações que desrespeitam a dignidade humana e ferem os direitos das pessoas e de parcelas inteiras da população. Essa capacidade tem possibilitado não só a denúncia, mas o engajamento em projetos de intervenção e a participação em entidades que desenvolvem ações concretas que têm como meta a construção de melhores condições para as crianças viverem a sua infância. Na verdade, o maior conhecimento da educação efetivamente oferecida às crianças e das perspectivas desses sujeitos sobre aspectos da sua experiência educativa fornecem argumentos fundamentais para tais ações.

Para concluir, quero declarar a minha saudade do diálogo com a Maria Helena. Saudade não só dos encontros de orientação, presenciais ou a 3.000 quilômetros de distância (numa época em que ainda não contávamos com a comunicação via internet), momentos em que realmente aprendi muito e foram marcados pela amizade, respeito, rigor e cuidado da Maria Helena. Mas também de outros encontros, que aconteceram em nossas casas, em São Paulo ou na casa de meus pais, em Fortaleza, no jardim zoológico, com o seu filho Daniel; ocasiões em que havia mais espaço para dar risadas, fazer desabafos, trocar receitas culinárias, falar das famílias, de tricô.

Por tudo isso, cultivo grande admiração e carinho pela Maria Helena.Tenho muito orgulho por ela ter sido a minha orientadora. E considero que, além disso, ela foi, de fato, a minha "amada mestra". 


\title{
Maria Helena, my supervisor
}

\begin{abstract}
Meeting Professor Maria Helena Patto at the undergraduate program in Psychology profoundly influenced my theoretical, political, and professional options. Her ideas and positions acquired more sense throughout her supervision when preparing my dissertation and doctoral thesis. In the dissertation, I heard a group of poor children to analyze the changes at the representation of school suffered during the first year of frequency in this institution. The thesis investigates how the school took control of the Basic Cycle, in order to understand the process of change they were getting through. In these studies, it became clear that it needs to grasp the perspective of various individuals who are part of educational institutions and seek to situate the historical facts, considering relations with the socio-economic, political and cultural context. That and the ability to get disgusted in situations that violate human dignity are a part of my learning from Maria Helena.
\end{abstract}

Keywords: Counselor characteristics. Educational counseling. Methodology. School environment.

\section{Maria Helena Patto, ma directrice de thèse}

Resumé: Avoir été élève de Mme Maria Helena Souza Patto en licence de Psychologie a profondément influencé mes options théoriques, professionnelles et politiques. Les idées et positions qui m'ont impressionnée se sont révélées significatives pendant sa direction de mon mémoire et de ma thèse. J'ai d'abord analysé (Master) les transformations de la représentation de l'école chez un groupe d'enfants pauvres pendant leur première année de scolarisation, à partir de leur écoute. J'ai ensuite étudié (Doctorat) comment l'école s'était appropriée du Cycle de Base (projet de l'état de São Paulo) en recherchant une meilleure compréhension du processus de changement. Il était nécessaire d'appréhender le point de vue des différents sujets appartenant aux institutions éducatives et de tenter de situer les faits en considérant leurs relations avec le contexte socio-économique, politique et culturel. Maria Helena m'a appris aussi à m'indigner devant les situations qui ne respectent pas la dignité humaine.

Mots-clés: Caractéristiques du superviseur. Orientation scolaire. Méthodologie. Environnement scolaire. 


\section{Maria Helena, mi orientadora}

Resumen: El encuentro con la profesora Maria Helena Patto en la graduación en Psicología ha influenciado profundamente mis opciones teóricas, profesionales y políticas. Sus ideas y posiciones fueran adquiriendo mejor sentido a lo largo de su orientación en la elaboración de mi disertación y de la tesis doctoral. La disertación examinó los cambios de la representación de escuela de un grupo de niños pobres durante su primer año de frecuencia en esa institución. La tesis investigó cómo la escuela comprendía el proyecto Ciclo Básico. En estos estudios, se quedó clara la necesidad de comprender las perspectivas de los varios sujetos que forman parte de las instituciones educativas y tratar de situar los hechos históricamente, teniendo en cuenta sus relaciones con el contexto socio-económico, político y cultural. Eso y la capacidad de me cuestionar delante de situaciones que violan la dignidad humana son parte de mi aprendizaje con Maria Helena.

Palabras clave: Características del consejero. Orientación educacional. Metodología. Ambiente escolar.

\section{Referências}

Andrade, R. C. (2007). A rotina da pré-escola na visão das professoras, das crianças e de suas famílias. Tese de Doutorado, Faculdade de Educação, Universidade Federal do Ceará, Fortaleza, CE.

Bosi, E. (1992). Entre a opinião e o estereótipo. Novos Estudos CEBRAP, 32, 111 118.

Campos, M. M., \& Cruz, S. H. V. (2006). Consulta sobre qualidade na educação infantil: o que pensam e querem os sujeitos desse direito. São Paulo:Cortez.

Cruz, S. H.V. (1987). A representação da escola em crianças da classe trabalhadora. Dissertação de Mestrado, Instituto de Psicologia, Universidade de São Paulo, São Paulo, SP.

Cruz, S. H. V. (1994). O Ciclo Básico construído pela escola. Tese de Doutorado, Instituto de Psicologia, Universidade de São Paulo, São Paulo, SP.

Cruz, S.H.V.(2002). Fala, menino! Uma experiência de pesquisa sobre o cotidiano da creche comunitária, na perspectiva da criança. Educação em Debate, 2(44), 20-35. 
Duran, M. C. G. (1989). Ciclo Básico em jornada única: uma nova concepção de alfabetização. In Congresso Latino Americano de Lectoescrita. Buenos Aires, Argentina. (Trabalho não publicado)

Ezpeleta, J., \& Rockwell, E. (1989). Pesquisa participante. São Paulo: Cortez.

Heller, A. (1987). Sociología de la vida cotidiana. Barcelona: Península.

Heller, A. (1992). O cotidiano e a história. Rio de Janeiro: Paz e Terra.

Mannoni, M. (1977). Educação impossível. Rio de Janeiro: Francisco Alves.

Martins, C. A. (2009). A participação de crianças e professora na constituição da brincadeira na educação infantil. Tese de Doutorado. Faculdade de Educação, Universidade Federal do Ceará, Fortaleza, CE.

Mollo, S. (1979). Les muets parlent aux sourds: les discours de l'enfant sur l'école. Paris: Casterman.

Patto, M. H. S. (1990). A produção do fracasso escolar: histórias de submissão e rebeldia. São Paulo:T. A. Queiroz.

Patto, M. H.S. (1997). Para uma crítica da razão psicométrica. Psicologia USP, 8(1), 47-62. doi: 10.1590/S0103-65641997000100004

Pichon-Rivière, E. (1982). O processo grupal. São Paulo: Martins Fontes.

Rockwell, E. (1982). De huellas, bardas y veredas: uma historia cotidiana de la escuela. In E. Rockwell \& R. Mercado, La escuela, lugar del trabajo docente: descripciones e debates. México: DIE.

Schramm, S. M. O. (2009). A construção do eu no contexto da educação infantil: influências da escola e a perspectiva da criança sobre esse processo. Tese de Doutorado, Faculdade de Educação, Universidade Federal do Ceará, Fortaleza, CE.

Trinca, W. (1997). Formas de investigação clínica em Psicologia: procedimento de desenhos-estórias, procedimento de desenhos de família com estórias. São Paulo: Vetor. 
Silvia Helena Vieira Cruz, Faculdade de Educação, Universidade Federal do Ceará. Endereço para correspondência: Rua Julio Lima, 300, casa 07, Cidade dos Funcionários, CEP: 60822-500, Fortaleza, CE, Brasil.Endereço eletrônico: silviavc@uol.com.br

Recebido: 20/11/2010

Aceito: 04/04/2011 